\title{
DEVELOPMENT OF A PAVEMENT RUTTING MODEL USING SHAKEDOWN THEORY
}

Mostapha Boulbibane, Faculty of Engineering, Sports and Sciences, University of Bolton, BL3 5AB, UK. Email: m.boulbibane@bolton.ac.uk

Ian F. Collins, Department of Engineering Science, University of Auckland, New Zealand. Email: i.collins@auckland.ac.nz.

doi: 10.1515/ijpeat-2015-0003

\begin{abstract}
The rutting of flexible pavements during their exploitation is considered to be one of the main problems in UK as well as worldwide. It is a serious mode of distress alongside fatigue in bituminous pavements that may lead to premature failure, as indicated by permanent deformation or rut depth along the wheel load path, and results in early and costly rehabilitation. This kind of pavement distress makes a negative impact to the serviceability characteristics of the flexible pavement, to the residual life of pavement structure and also to the safety and ride quality for traffic. Two design methods have been used to control rutting: one to limit the vertical compressive strain on the top of subgrade and the other to limit rutting to a tolerable amount usually around "12 mm". Although experimental data and practical experience have been introduced into these design methods through empirical parameters, there is not a simple relationship between the elastic strain and the long-term plastic behaviour of pavement materials. This paper describes a method based on the kinematic shakedown theorem for constructing a mathematical model to predict the long-term behaviour of pavement structures under the action of repeated and cyclic loadings imposed by moving traffic. This method seeks the mechanism from within a class of mechanisms that minimises the shakedown limit load for pavement structures consisting of layers of Mohr-Coulomb materials. The model differs from extant models, in that the cyclic nature of the loading on a pavement is recognised from the outset, and the current method which is based upon foundation analysis, is replaced by a procedure employing shakedown theory that features the capabilities and applications of the developed technique for assessing rutting in flexible pavements. The basic concepts are outlined together with the most recent calculations of the critical design shakedown load. The influence of the design parameters such as, the strength, stiffness and depth of the granular base-course material as well as the consequences of traffic loading (number of equivalent standard axel loads - ESAL's) are discussed.
\end{abstract}

Keywords: Flexible pavement, rutting, shakedown theory, cyclic loads

\section{Introduction}

Flexible pavements are often subjected to mixed heavy traffic loading and varying environmental conditions which highly influence their performances in terms of distress developments i.e. cracking often associated with the growth of strain near the contacted surface and compressive permanent deformation which generally results in a rut formation. The accurate prediction of their development is an essential input for 
the efficient management of pavement structures and thus in allocating cost responsibilities to various vehicle classes for their use of the highway system. Although design procedures are becoming more "mechanistic" and sophisticated by introducing experimental data and practical experience through empirical formulae, there is not a simple relationship between the elastic strain and the long-term plastic behaviour of pavement materials. Specifically nearly all pavement design models concentrate on the resilient "elastic" behaviour of the various pavement layers (e.g. tensile strain at the bottom of HMA and the vertical compressive strain at the top of the sub-grade) and the "life" of the pavement estimated using empirical formulae relating these strains to the number of "standard" load applications. Presumably these procedures can sometimes indicate a long pavement life. However, the observed performance (rutting, surface integrity and roughness) can indicate much shorter lives. It is not a question of designing for a certain number of load applications, as at present, but rather a question of whether the "damage" to the pavement is transitory, or whether it will accumulate indefinitely, resulting in an early failure. There is hence a clear need to develop a mechanistic design approach to flexible pavement design, which incorporates the plastic as well as elastic properties of the pavement layers and provides long term prediction.

A number of research papers have suggested the use of bearing capacity theory to predict the "failure" of pavements (Houlsby and Burd, 1999; Michalowski and Shi, 1995; Oloo et al., 1997). These papers use conventional limiting equilibrium or limit analysis techniques, which of course do not model the repetitive nature of the loading history. The procedure advocated in the present paper which is based upon the shakedown theory allows the cyclic nature of the pavement loading to be modelled and incorporates both the elastic and plastic responses of the pavement to these loads. It is mainly based on assuming a certain class of failure mechanisms. Apart from the material deterioration in the pavement, the structure hardening due to residual stress in the pavement is considered through the shakedown limit loads. The concept of shakedown is highly relevant to the design of any structure which exhibits elastic and plastic responses to the application of repetitive loads. A number of authors have described solutions of this problem in terms of shakedown limits, assuming particular simple classes of plastic deformation patterns using either upper shakedown theorem (Collins et al., 1993; Collins and Boulbibane, 2000) or lower bound shakedown theorem (Yu and Hussain, 1998; Raad and Minassian, 2005).

In this paper we discuss a simplified approach that has the potential of predicting the load-induced deformation, e.g. rutting of flexible pavements. The method differs from extant models, in that the cyclic nature of the loading on a pavement is recognised from the outset, and the current method, which is based upon foundation analysis is replaced by a procedure employing shakedown theory. In essence this method seeks the mechanism, from within a class of mechanisms that minimises the shakedown limit load. A simplified illustrative example is given to show how the procedure might be utilised. Extensive computer analyses based on the elastic layer program BISAR developed by De Jong et al. (1979) and global optimisation, the Simulated Annealing procedure devised by Goffe et al. (1994), are conducted to simulate rutting in the asphalt surfaces, granular base-courses, and subgrades. Also investigations into the relative structural contributions of wearing course and granular base-course to the load carrying capacity of the pavement structure, when used at different layer 
thicknesses/or different materials, are studied and implications for design procedures are discussed.

\section{Classic Rut Formation Model}

It is commonly understood that pavement rutting, defined as longitudinal depressions in the wheel paths of asphalt pavements, develops within pavement layers when traffic loading causes layer densification and/or when stresses induced in the pavement materials are sufficient to cause shear displacements within the materials. The layer(s) in which rutting occurs is determined by loading magnitude and the relative strength of the pavement layers e.g. wearing course, granular base-courses and subgrade. Numerous models have been used to relate vertical compressive strain accumulation $\left(\varepsilon_{\mathrm{v}}\right)$ to the number of load or stress repetitions $\left(N_{f}\right)$. Further details on development of fatigue and rutting equations can be obtained from any standard text books (Yoder and Witczak, 1975; Huang, 1993). By far, the most common model found in the literature is of the form:

$N_{f}=a\left(\varepsilon_{\mathrm{v}}\right)^{b}$

Where $a=1.365 \times 10^{-9}$ and $b=-4.477$ are terms developed from field calibration data as suggested by Claros and Hudson (1992). The above equation defines failure as $12.5 \mathrm{~mm}$ (0.5-inch) depressions in the wheel-paths of the pavement. Similarly from the empirically calibrated AASHTO road test it is found that pavement deterioration in terms of damage occurring from an $80 \mathrm{kN}$ axle load appeared to have a fourth power relationship to the actual axle load applied to the pavement:

$N_{f}=N \times\left(P / P_{s}\right)^{4}$

In which $N$ is the number of the repetitions of load $P$ and $P_{S}$ is the standard axle load. By substituting equation (2) into (1), the following relationship between the load $P$ and the critical strain for a given pavement thickness profile becomes:

$P^{0.8934} \times \varepsilon_{\mathrm{v}}=0.0129$

The vertical compressive strain at the top of the sub-grade is calculated using e.g. the elastic layer program BISAR developed by De Jong et al. (1979) and the "life" of the pavement is estimated assuming the "acceptable" life being $N=10^{6}$. Clearly this expression indicates that all pavements gradually deteriorate, however experimental observations suggest that if one operates below a critical design load, the pavement structure does not deteriorate indefinitely.

\section{Proposed Method}

It has been recognised for some years now that shakedown theory may well provide the key to a more rationally based pavement design procedure. In particular it is suggested that the concept of the "shakedown load" should be the basic design parameter. If the pavement is subjected to a repeated loading cycle with the maximum load below this critical load, then the long term response of the pavement will be 
purely elastic, although the response may well be plastic for a finite number of initial load applications. Some irrecoverable strains will be accumulated, but the total plastic strain will be bounded. In this situation the pavement is said to have "shakedown". For higher operating loads the pavement will "fail" in the sense that permanent deformations of some sort will continue to build up indefinitely resulting in either surface cracking and or pavement rutting.

The dual upper bound theorem due to Koiter (Lubliner, 1990) stated in a form appropriate for the pavement problem is that if $\dot{\varepsilon}_{i j}^{p}$ denotes any time-independent strain rate field describing a possible failure mechanism, with associated plastic stress field $\sigma_{i j}^{p}$, associated with the assumed kinematically admissible velocity field and $\sigma_{i j}^{e}$ is the elastic stress field produced by the applied cyclic load $P$, then the actual shakedown load multiplier $(\lambda)$ satisfies the inequality:

$$
\lambda \leq \frac{\int_{V} \sigma_{i j}^{p} \dot{\varepsilon}_{i j}^{p} d V}{\int_{V} \sigma_{i j}^{e} \dot{\varepsilon}_{i j}^{p} d V}
$$

and hence provides an upper bound of the true limit load multiplier inducing collapse. Both integrals in eq. 4, represent the rate of plastic dissipation and the virtual rate of dissipation of the elastic stress field in the proposed failure mechanism, respectively, are evaluated over the cross-section of the failure mode, orthogonal to the travel direction. It is similar to the classic technique of limit analysis, except that the calculation involves knowledge of the elastic stress distribution. In the calculations described here we choose mechanisms in which the plastic dissipation is confined to discrete slip lines, as illustrated in Figure 1(b). Thus, following Chen (1975), for a Coulomb material, the two dissipation functions in equation (5) reduce to:

$\lambda \leq \frac{c \sum_{i=1}^{n}\left[\mathrm{v}_{t i}\right] l_{i}}{\sum_{i=1}^{n}\left[\mathrm{v}_{t i}\right] \int c_{i}^{e} d l_{i}}$

where $c$ is the cohesion, and $\left[\mathrm{v}_{t i}\right]$ and $l_{i}$ are, respectively, the jump in tangential velocity and length of the $i^{\text {th }}$ discontinuity, whilst $c_{i}^{e}$ is termed the elastic cohesion and can be evaluated along slip lines by:

$$
c_{i}^{e}=\left|\sigma_{t}^{e}\right|-\sigma_{n}^{e} \tan \phi
$$

In this investigation, we are mostly concerned with rut failure in three layered pavement structures as illustrated in Figure 1(b). Such failure mode is described by geometric parameters $\left(\alpha_{i, j}, D\right.$ and $x_{o}$ defining the position of the $(y, z)$ plane of deformation). Furthermore, the slip lines must change in slope as they cross the asphalt/basecourse and basecourse/subgrade boundaries whenever the value of the internal friction angle $\phi_{j}$ is different in the three layers according to the following relationship:

$$
\alpha_{i, j}-\phi_{j}=\alpha_{i, j+1}-\phi_{j+1} \quad \text { with } \quad i, j=1,2,3
$$

The optimum solution is then found by varying the defining geometric parameters so as to minimize the ratio given by Eq. 5 and hence find the best upper bound $(\lambda)$, out of 
the class of mechanisms being considered. The control parameter in the algorithm is set initially to high value decreased in steps until the optimal solution is found. This minimization is performed using a simulated annealing procedure (Goffe et al., 1994).

\section{Applications}

The proposed numerical method is applied to study the influence of granular characteristics and layers thicknesses on the performance of pavement structures. All pavement structures are modelled as semi-infinite linear elastic system consisting of three layers, which are wearing, granular base-course and subgrade. The subgrade is modelled as a purely cohesive material. Typical pavement sections and material characteristics considered in this study are summarised in Table 1. An equivalent 80$\mathrm{kN}$ single-axle load with single tires is used. It's assumed that the tire load is uniformly applied over a circular area (radius $=150 \mathrm{~mm}$ ). The contact pressure is assumed to equal the tire inflation pressure of $560 \mathrm{kPa}$ (this is not exactly true, but adequate for approximations). Under axisymmetric condition the resulting stress distributions within each layer of a pavement structure are determined by applied load, individual and combined layer thickness, and layer material properties. The analysis is performed on a soft and stiff subgrades, each with various layer thickness combinations.

(a)

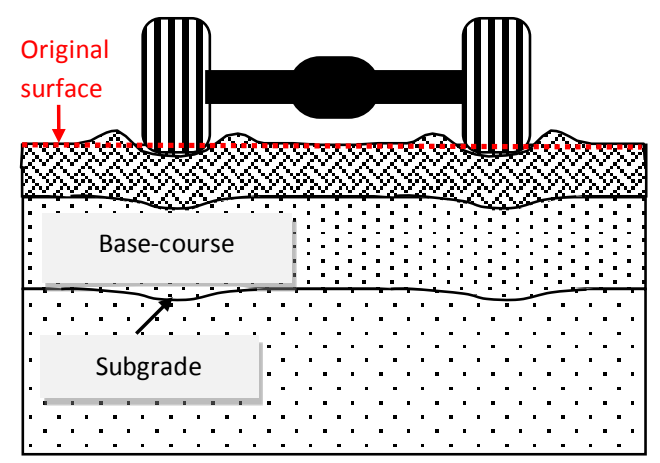

(b)

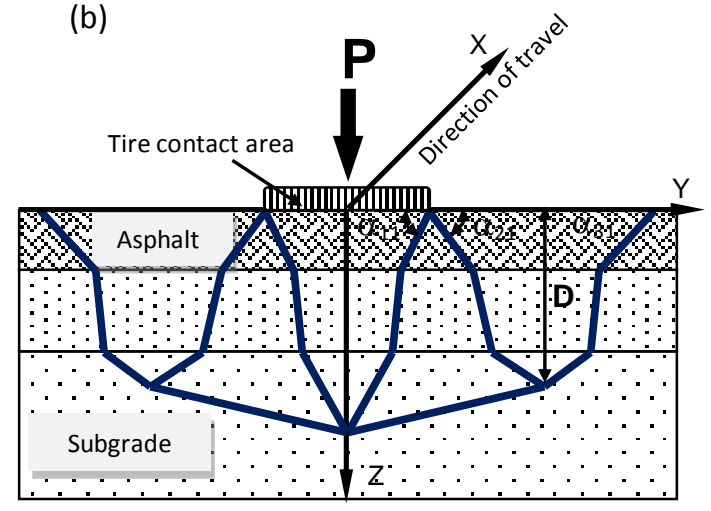

Figure 1. (a) Failure due to rutting, (b) proposed rut failure mechanism

Table 1. Properties of pavement layers

\begin{tabular}{cccccc}
\hline Layer & $\begin{array}{c}\text { Elastic } \\
\text { modulus } \\
{[\mathrm{MPa}]}\end{array}$ & $\begin{array}{c}\text { Poisson's } \\
\text { ratio } \\
v\end{array}$ & $\begin{array}{c}\text { Layer thickness, } \\
\mathrm{h} \\
{[\mathrm{mm}]}\end{array}$ & $\begin{array}{c}\text { Friction } \\
\text { angle, } \phi \\
{\left[{ }^{\circ}\right]}\end{array}$ & $\begin{array}{c}\text { Cohesion, } \\
\mathrm{c} \\
{[\mathrm{kPa}]}\end{array}$ \\
\hline Asphalt Concrete & 4,000 & 0.35 & $50,100,150,200$ & 17 & 4,500 \\
\hline Granular Base Type I & 150 & 0.35 & $150,250,400,500$ & 45 & 20 \\
\hline Granular Base Type II & 250 & 0.35 & $150,250,400,500$ & 45 & 60 \\
\hline $\begin{array}{c}\text { Soft Subgrade } \\
\text { (fine grained) }\end{array}$ & 20 & 0.45 & Infinite & 0 & 20 \\
\hline $\begin{array}{c}\text { Stiff Subgrade } \\
\text { (fine grained) }\end{array}$ & 80 & 0.45 & Infinite & 0 & 80 \\
\hline
\end{tabular}


Initial results suggest that shakedown limits are influenced by the geometry of the assumed failure mechanism. It is found that mechanism when described by a single variable $\left(\alpha_{1, j}=\alpha_{2, j}=\alpha_{3, j}=\alpha\right)$ gives a higher estimate of the shakedown limit than when it is described by more than one variable $\left(\alpha_{1, j} \neq \alpha_{2, j} \neq \alpha_{3, j}\right.$ and $\left.D\right)$. Some preliminary results of calculations for this situation are given in Table 2. At convergence a typical failure mode obtained for rut formation is illustrated in Figure 3. This failure is much narrower than for static analysis (e.g. Atkinson, 1981; Bolton and Lau 1993) for the plane and axisymetric solutions. Details of other modes considered may be found in (Collins and Boulbibane, 2000; Boulbibane et al., 2005; Boulbibane and Mohamed, 2012).

Table 2. Shakedown limits for three-layered pavement structures [MPa]

\begin{tabular}{ccccccc}
\hline Number of parameters & \multirow{2}{*}{\begin{tabular}{c} 
Type of \\
\cline { 3 - 7 }
\end{tabular}} & \multicolumn{5}{c}{ Thickness of Granular Base Type I } \\
\cline { 3 - 7 } $\mathrm{h}_{\mathrm{b}}[\mathrm{mm}]$ \\
\hline$\alpha_{1, \mathrm{j}}=\alpha_{2, \mathrm{j}}=\alpha_{3, \mathrm{j}}$ and $\mathrm{x}_{0}$ & Subgrade & 100 & 150 & 250 & 400 & 500 \\
\hline$\alpha_{1, \mathrm{j}} \neq \alpha_{2, \mathrm{j}} \neq \alpha_{3, \mathrm{j}}, \mathrm{D}$ and $\mathrm{x}_{0}$ & Soft & 2.49 & 2.76 & 3.10 & 3.42 & 3.56 \\
\hline$\alpha_{1, \mathrm{j}}=\alpha_{2, \mathrm{j}}=\alpha_{3, \mathrm{j}}$ and $\mathrm{x}_{0}$ & Stiff & 3.51 & 3.69 & 3.98 & 4.26 & 4.38 \\
\hline$\alpha_{1, \mathrm{j}} \neq \alpha_{2, \mathrm{j}} \neq \alpha_{3, \mathrm{j}}, \mathrm{D}$ and $\mathrm{x}_{0}$ & Stiff & 2.91 & 3.07 & 3.37 & 3.65 & 3.79 \\
\hline
\end{tabular}

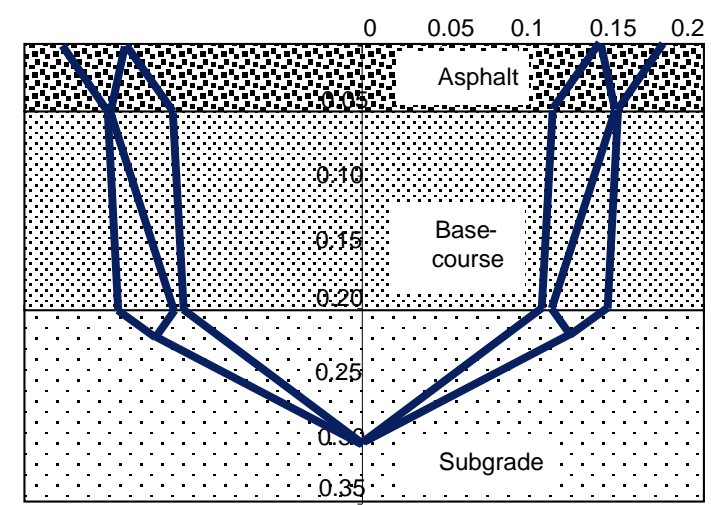

Figure 2. Optimal rut mechanism for three layered pavement structure

To get an appropriate picture of the size of influence of layer thickness and material properties, some calculations of response are made and presented in graphs below. For a given layered pavement (Figure 1) with known material parameters, the shakedown limits are determined from shakedown analysis and compared against the design traffic loads. The design traffic load obviously has to be less than the shakedown load to ensure that accumulation of permanent strains will not occur. In the case the design traffic load is much smaller than the shakedown limit load, the design of the pavement is conservative and the adjustment of the granular base-course thickness should be made. The variations of $\left(\varepsilon_{\mathrm{v}}\right)$ with $\left(h_{\mathrm{b}}\right)$, the depth of the granular base-course according to equation (3), can be found from the program BISAR with a dual load of $40 \mathrm{KN}$ - giving a non-linear load-depth relation for both soft and stiff subgrades. In these calculations the thickness of the granular base-course layer and the 
radius of the loaded are taken to be $250 \mathrm{~mm}$ and $150 \mathrm{~mm}$ respectively. The variation of the applied pressure with the thickness of the granular base-course layer is illustrated in Figure 3 for three layered pavement structures with soft/stiff subgrades.
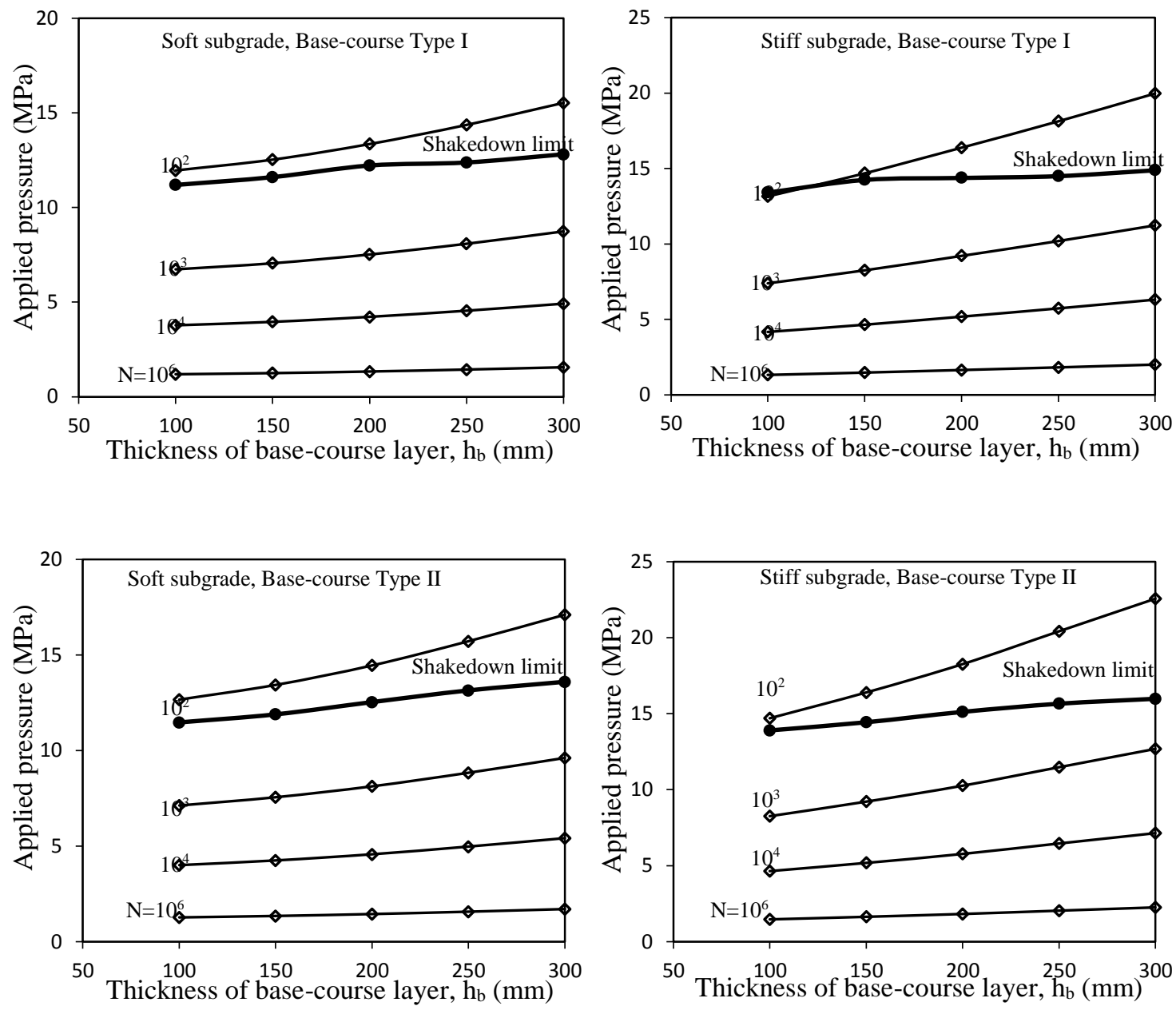

\section{Figure 3. Dependence of the axle load on granular base-course thickness for given load repetitions}

It can be seen that pavement loading associated with rutting of the subgrade, is lower or higher than the shakedown limit, depending on applied load repetitions and pavement component characteristics. It should be emphasised though that for larger load repetitions used in conventional mechanistic pavement design (generally $>10^{6}$ ), it seems that the shakedown load is essentially higher than the applied design load. From these figures, it is also seen that as the depth increases, the shakedown load approaches a finite limiting value whilst the design load increases indefinitely. This means that there is a critical thickness of the granular base-course layer for which the shakedown load would become more critical than the design load obtained by the existing design method (Eq. 3).

Results shown in Figure 4 indicate that increasing the thickness of the asphalt layer could have a significant effect on the increase in shakedown resistance of the pavement. This increase is more for pavements with stiff subgrade compared to soft 
subgrade. The shakedown resistance also increases with increased thickness of the granular base-course as illustrated in Figure 3. However, this increase is less significant than that observed when the asphalt layer is increased. Changing the thickness of the asphalt layer will have enormous impact on the shakedown limit with an increase of $70 \%$. Also improving the base properties in terms of modulus and shear strength i.e. cohesion and/or friction angle, results in improved shakedown resistance as shown in Figure 4.
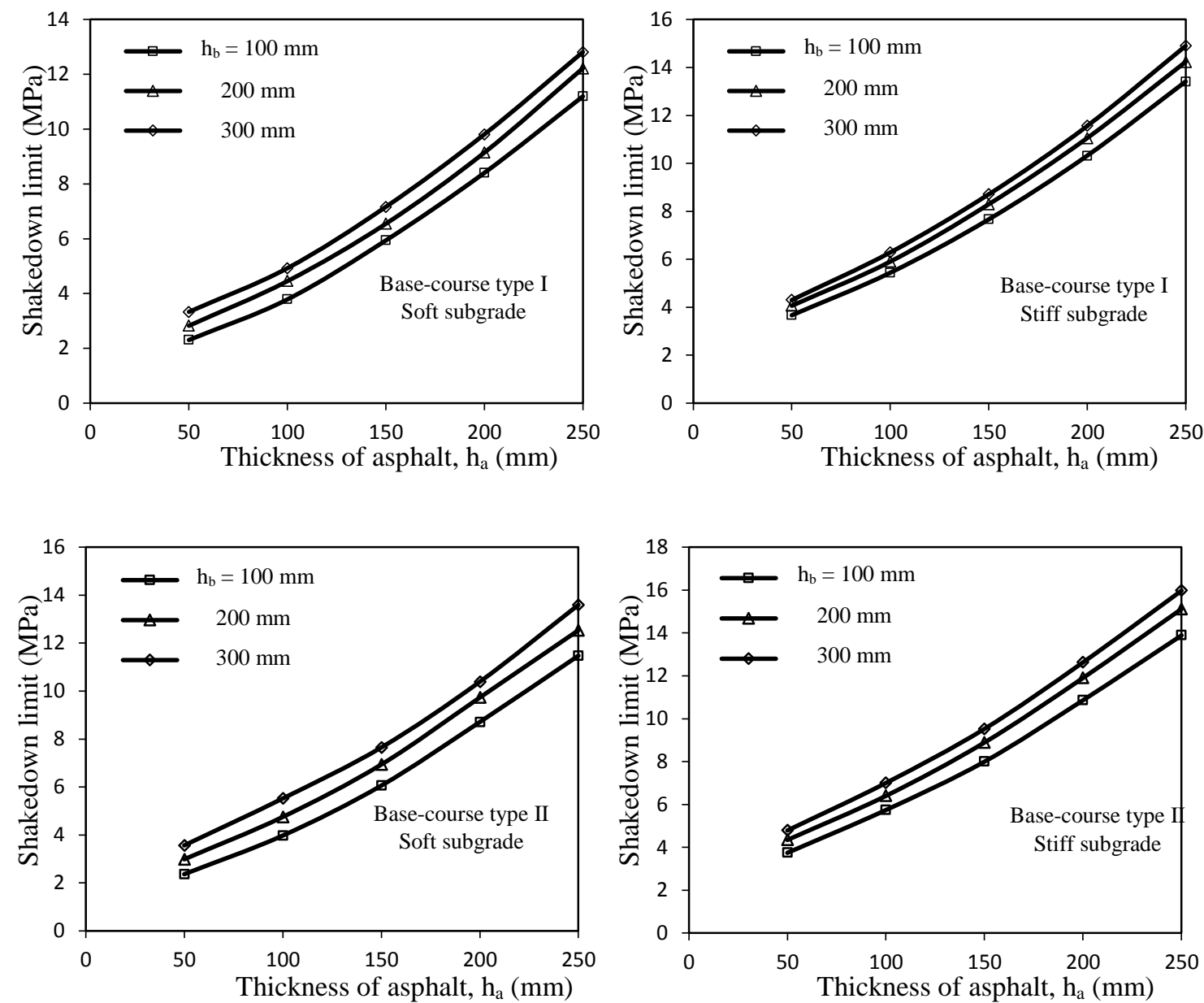

\section{Figure 4. Influence of thickness of asphalt layer on shakedown limit for various granular base-course types}

A similar tendency in term of relationships between shakedown and the thickness of the asphalt and/or the granular base-course (Type $\mathrm{I}$ and $\mathrm{h}_{\mathrm{b}}=150 \mathrm{~mm}$ ) can be observed from Raad and Minassian (2005) research for similar pavement structures, although the shakedown limits are slightly different. 


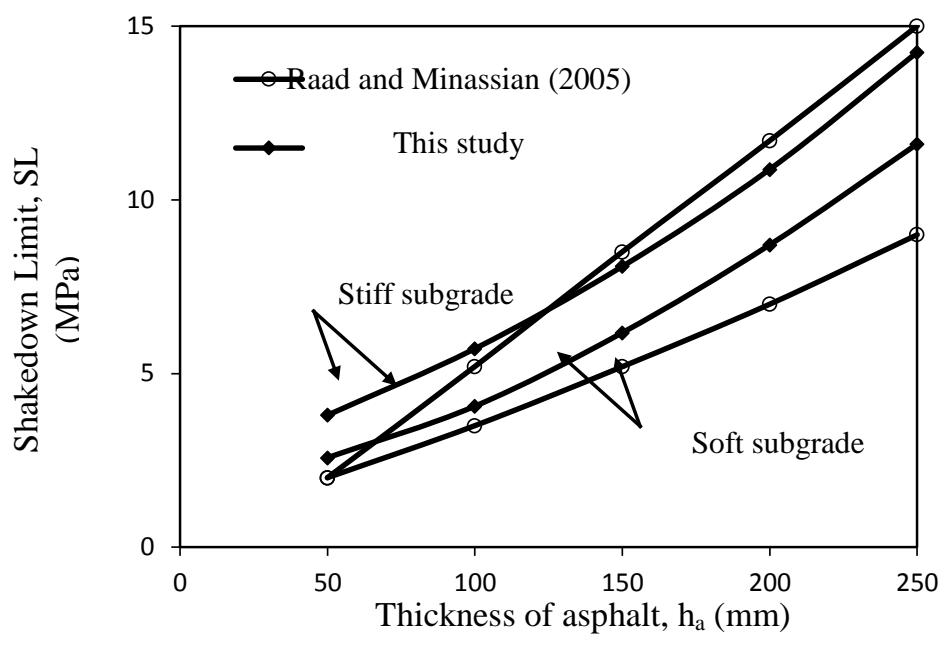

\section{Figure 5. Influence of thickness of asphalt layer on shakedown limit for various subgrade types}

\section{Conclusions}

This paper describes a technique based on the kinematic shakedown theorem to predict the long-term behaviour of pavement structures under the action of repeated and cyclic loadings imposed by moving traffic. It is employed in an attempt to accurately determine the shakedown limits for road materials, and to reasonably model the various failure mechanisms occurring in pavements. The conventional Mohr-Coulomb yield criterion is assumed for the various pavement layers determined by their cohesions and frictions angles. Using this technique, sensitivity analyses were conducted to study the influences of asphalt layer thickness, granular base-course layer thickness and subgrade condition on the deterioration rate of pavements. Also mathematical correlations between the allowable number of load cycles and the magnitude of axle loads were developed, incorporating the main factors influencing the pavements behavior and taking into account the load conditions. Results of analyses indicate that shakedown criterion should be considered in the design and evaluation of pavement structures. A pavement designed to resist a number of load applications in fatigue would exhibit increased accumulation of plastic strains if the applied load exceeds the shakedown capacity, but the pavement would reach a steady state response if the applied load were smaller than the shakedown capacity. The computation performed to date provides a rational basis for studying the consequences of variations in the design variables such as the strength, stiffness and depth of layers constituent pavement structures, as illustrated, and hence enables some preliminary design charts to be constructed for multi-layered pavements. Although further experimental field and theoretical research is needed, this new approach to pavement design would provide the industry with an extremely valuable analytical tool.

\section{References}

Atkinson, J.H. (1981). "Foundations and slopes". McGraw-Hill Book Company (UK). Bolton, M.D. and Lau, C.K. (1993). "Vertical bearing capacity factors for circular and strip footings on Mohr-Coulomb soil." Canadian Geotech. J., No. 30, pp 1024-1033. 
Boulbibane, M., Collins, I.F., Ponter, A.R.S. and Weichert, D. (2005). "Shakedwon of unbound pavements". Road Materials and Pavement Design 6 (1), pp 81-96.

Boulbibane, M. and Mohamed A.A. (2012). "Design of unbound pavement layer material based upon the shakedown concept". Applied Mechanics and Materials Vols. 174-177, pp 726-732.

Chen, W.F. (1975). "Limit analysis and soil plasticity”. Elsevier, Amsterdam.

Claros, G. and Hudson, W.R. (1992). "Development of an overlay design method for flexible pavements on lateritic soils". Proceedings of $7^{\text {th }}$ International Conference of asphalt pavements, Nottingham University, pp 3-53.

Collins, I.F. and Boulbibane, M. (2000). "Geotechnical analysis of unbound pavements based on shakedown theory". J. of Geotechnical and Geoenvironmental Engineering, 126, No., pp 50-59.

Collins, I.F., Wang, A.P. and Saunders, L.R. (1993). "Shakedown in layered pavements under moving surface loads." Int. J. Num. and Anal. Methods in Geomechanics, 17, pp 165-174.

De Jong, D.L., Peutz, M.G.F. and Korswagen, A.R. (1979). "Computer Program Bisar”. Shell, Amsterdam.

Goffe, B., Ferri, G. D. and Rogers, J. (1994). "Global optimization of statistical functions with simulated annealing”. Journal of Econometrics, Vol. 60, pp 65-99.

Houlsby, G.T. and Burd, H.J. (1999). "Understanding the behaviour of unpaved roads on soft clay." Proceedings of the $12^{\text {th }}$ European Conference on Soil Mechanics and Geotechnical Engineering - Geotechnical Engineering for Transportation Infrastructure, Amsterdam, 7-10 June.

Huang, Y.H. (1993). "Pavement Analysis and Design”. Prentice-Hall, New Jersey. Lubliner, J. (1990). "Plasticity theory", Macmillan, New York.

Michalowski, R.L. and Shi, L. (1995). "Bearing capacity of footings over two-layer foundation soils. " J. of Geotechnical Engineering, pp 421-428.

Oloo, S.Y., Fredlund, D.G. and Gan, J.K.M. (1997). "Bearing capacity of unpaved roads". Canadian Geotech. J., 34, pp 398-407.

Raad, L. and Minassian, G. (2005). "The influence of granular base characteristics on upper bound shakedown of pavement structures". Road Materials \& Pavement Design 6, pp 53-79.

Yoder, E.J. and Witczak, M.W. (1975). "Principles of Pavement Design". 2nd ed. John Wiley and Sons, New York. 
Yu, H.S. and Hossain, M.Z. (1998). "Lower bound shakedown analysis of layered pavements using discontinuious stress fields". Computer Methods in Applied Mechanics and Engineering, Vol. 167, pp 209-222. 